\title{
A Method of Assessment of Human Natural Killer Cell Phenotype and Function in Whole Blood
}

\author{
Marisa Market ${ }^{1}$, Gayashan Tennakoon ${ }^{2}$, Juliana $\mathrm{Ng}^{2}$, Marlena Scaffidi ${ }^{1}$, \\ Christiano Tanese de Souza ${ }^{2}$, Michael A. Kennedy ${ }^{2}$ and Rebecca C. Auer ${ }^{2,3 *}$ \\ 1 University of Ottawa, Ottawa, ON, Canada, ${ }^{2}$ Cancer Therapeutics Program, Ottawa Hospital Research Institute, Ottawa, \\ ON, Canada, ${ }^{3}$ Department of Surgery, University of Ottawa, The Ottawa Hospital, Ottawa, ON, Canada
}

\section{OPEN ACCESS}

Edited by:

Eleanor Riley,

University of Edinburgh

United Kingdom

Reviewed by:

Martin R. Goodier,

University of London, United Kingdom

Salim Iqbal Khakoo

University of Southampton,

United Kingdom

*Correspondence:

Rebecca C. Auer rauer@ohri.ca

Specialty section: This article was submitted to NK and Innate Lymphoid Cell Biology, a section of the journal

Frontiers in Immunology

Received: 04 February 2020 Accepted: 23 April 2020

Published: 20 May 2020

Citation:

Market M, Tennakoon G, Ng J, Scaffidi M, de Souza CT, Kennedy MA and Auer RC (2020) A Method of Assessment of Human Natural Killer Cell Phenotype and Function in Whole Blood. Front. Immunol. 11:963. doi: 10.3389/fimmu.2020.00963
The majority of data on human Natural Killer (NK) cell phenotype and function has been generated using cryopreserved peripheral blood mononuclear cells (PBMCs). However, cryopreservation can have adverse effects on PBMCs. In contrast, investigating immune cells in whole blood can reduce the time, volume of blood required, and potential artefacts associated with manipulation of the cells. Whole blood collected from healthy donors and cancer patients was processed by three separate protocols that can be used independently or in parallel to assess extracellular receptors, intracellular signaling protein phosphorylation, and intracellular and extracellular cytokine production in human NK cells. To assess extracellular receptor expression, $200 \mu \mathrm{L}$ of whole blood was incubated with an extracellular staining (ECS) mix and cells were subsequently fixed and RBCs lysed prior to analysis. The phosphorylation status of signaling proteins was assessed in $500 \mu \mathrm{L}$ of whole blood following co-incubation with interleukin (IL)-2/12 and an ECS mix for 20 min prior to cell fixation, RBC lysis, and subsequent permeabilization for staining with an intracellular staining (ICS) mix. Cytokine production (IFN $\gamma$ ) was similarly assessed by incubating $1 \mathrm{~mL}$ of whole blood with PMA-ionomycin or IL-2/12 prior to incubation with ECS and subsequent ICS antibodies. In addition, plasma was collected from stimulated samples prior to ECS for quantification of secreted IFN $\gamma$ by ELISA. Results were consistent, despite inherent inter-patient variability. Although we did not investigate an exhaustive list of targets, this approach enabled quantification of representative ECS surface markers including activating (NKG2D and DNAM-1) and inhibitory (NKG2A, PD-1, TIGIT, and TIM-3) receptors, cytokine receptors (CD25, CD122, CD132, and CD212) and ICS markers associated with NK cell activation following stimulation, including signaling protein phosphorylation (p-STAT4, p-STAT5, p-p38 MAPK, p-S6) and IFN $\gamma$ in both healthy donors and cancer patients. In addition, we compared extracellular receptor expression using whole blood vs. cryopreserved PBMCs and observed a significant difference in the expression of almost all receptors. The methods presented permit a relatively rapid parallel assessment of immune cell receptor expression, signaling protein activity, and cytokine production in a minimal volume of whole blood from both healthy donors and cancer patients.

Keywords: natural killer cells, whole blood, flow cytometry, cytokine stimulation, interferon gamma, NKG2D 


\section{INTRODUCTION}

Natural Killer (NK) cells, first identified by Kiessling et al. in 1975, are cytotoxic lymphocytes that play a critical role in the innate immune response through the destruction of stressed, infected, or cancerous cells (1). Defective NK cell function has been linked to autoimmune and infectious diseases as well as cancer (2-6). Our investigations focus on understanding the suppression of NK cells following surgery in cancer patients and the impact of immunosuppression on metastasis. Specifically, our lab and others have shown that postoperative defects in NK cell cytotoxicity and IFN $\gamma$ production contribute to increased metastasis in models of surgical stress (7-9). Our initial observations of this suppressed phenotype were in cryopreserved peripheral blood mononuclear cells (PBMCs); however, we have also observed this phenomenon in whole blood. We then developed protocols that can be used in parallel to assess the phenotype, intracellular signaling following cytokine stimulation, and cytokine production of immune cells, and as an example, in this paper we highlight its implementation for our ongoing research investigating NK cells in cancer patients.

For practical reasons, the majority of the data on human NK cells has been generated using PBMCs. For instance, cryopreservation allows for running batched samples simultaneously as well as logistical flexibility for the storage and shipment of samples between research facilities (10). Using this approach, the study of cryopreserved PBMCs through functional and phenotypic assays has yielded a great deal of understanding about the role of NK cell function in disease. However, the use of cryopreserved PBMCs in immunologic studies is associated with adverse effects on cell populations/certain cell markers and altered gene expression (11-13). As a result, our understanding of NK cells may benefit in certain circumstances from investigations of non-cryopreserved cells.

In trying to assess the mechanism of NK cell dysfunction in cancer patients in the context of surgery, we sought to assess key markers and intracellular pathways associated with this dysfunctional NK cell phenotype. We investigated upstream receptor expression and subsequent signaling protein phosphorylation in order to elucidate the mechanism of NK cell suppression. NK cells do not undergo clonal selection, they instead express a limited number of germline-encoded receptors (14). NK cell activating receptors recognize pathogen-derived antigens as well as stress-induced ligands in what is termed the "induced-self recognition model" (15-17). These activating signals are antagonized by inhibitory receptors that recognize constitutively expressed self-molecules or inhibitory checkpoint proteins $(15,16)$. We sought to assess the expression levels of the activating receptors NKG2D and DNAM-1 and the inhibitory receptors NKG2A, PD-1, TIGIT, and TIM-3. In addition to these receptors, NK cells also express a plethora of cytokine receptors, including interleukin (IL)-2R and IL-12R (18). NK cell activity is thus regulated by the integration of activating and inhibitory ligands through these many receptors, which results in phosphorylation and signal transduction through signaling proteins such as STAT4, STAT5, p38 MAPK, and S6 $(9,19-23)$. This culminates in the regulation of transcription factor activity that controls the transcription of cytokines such as IFN $\gamma$ and cytotoxic proteins, including granzymes and perforin $(24,25)$. In characterizing the perioperative NK cell phenotype, we found it challenging to assess phosphorylation status in cryopreserved PBMCs. As a solution, we considered the use of whole blood, which proved to be far superior. In the troubleshooting process we also discovered a discrepancy between the phenotypes observed in cryopreserved PBMCs vs. whole blood staining. The successes we experienced by using whole blood samples, compared to cryopreserved PBMCs, prompted us to continue using whole blood samples for assessment of NK cell activity and develop a series of easily implemented, standardized protocols that enable a comprehensive investigation of NK phenotype and function.

There is a paucity of studies investigating immune cell function from whole blood (26). We posit that such studies would avoid the adverse effects of cryopreservation and provide more biologically relevant results in some circumstances. For example, investigating protein phosphorylation states by flow cytometry is difficult in cryopreserved samples due to the poor signal to noise ratio of the target protein compared to investigations in whole blood samples (27). Many of these limitations can be overcome by staining directly in whole blood, which also allows for simpler and faster protocols that require minimal manipulation of the cells of interest and therefore support the biological relevance of the results. A limitation of whole blood assays includes having to process patient samples immediately and therefore they cannot be tested simultaneously, which could lead to greater inter-assay variability. However, technical expertise, appropriate controls, and validated standard operating procedures can be implemented to help mitigate this limitation.

Comparisons of immunologic assays using cryopreserved PBMCs and whole blood samples have previously been reported and is not the focus of our report $(24,25,28)$. Here we sought to highlight the feasibility and advantages of using whole blood samples as a strategy for phenotypic and functional assessments in NK cells. As a proof of concept, we show the utilization of these protocols in our ongoing research. We explored the differential expression of phenotypic receptors necessary for NK activity and phosphorylation of downstream signaling molecules in healthy donors and cancer patients using whole blood. Finally, NK cell function was investigated by quantifying intracellular and extracellular IFN $\gamma$ by flow cytometry and ELISA following stimulation with PMA-ionomycin or IL-2/IL-12. We show that assaying cryopreserved cells results in altered NK cell phenotype in human patients as compared to whole blood analysis. In addition, we outline in detail novel whole blood protocols that can be used in parallel to assess immune cell receptor expression, signaling protein phosphorylation, and cytokine production. Although developed to assess NK cell activity in the perioperative period, these protocols could be used to assess other immune cell phenotypes in other pathological conditions.

\section{MATERIALS AND EQUIPMENT}

Equipment required includes a $37^{\circ} \mathrm{C}$ incubator, a $37^{\circ} \mathrm{C}$ water bath, a centrifuge, an ELISA Microplate Reader, and a flow cytometer (LSR Fortessa). Sodium-heparin tubes (BD Vacutainer ${ }^{\circledR}$ Cat $\# 367878 / 367874$ ) were used to collect 
healthy donor and patient blood samples. Stimulation reagents included PMA (phorbol 12-myristate 13-acetate; Sigma Aldrich Cat \#P8139), Ionomycin (Sigma-Aldrich Cat \#I9657-1MG), recombinant human IL-2 (Tecin Teceleukin) and recombinant human IL-12 (R\&D System Cat \#219-IL005). Reagents used in staining protocols include: Phosphate Buffered Saline (PBS), BD Golgiplug (Brefaldin A) (Cat \#51-2301K2), BD FACS Lyse/ Fix Buffer (Cat \#558049), deionized/ distilled $\mathrm{H}_{2} \mathrm{O}$, Flow Buffer (PBS $+2.5 \mathrm{~g}$ BSA + 0.5M EDTA), BD Perm III Buffer (Cat \#558050), and $1 \%$ Paraformaldehyde. Extracellular IFN $\gamma$ was quantified using the R\&D Quantikine Human IFN $\gamma$ ELISA (Cat \#DIF50). Antibodies used for FACS staining are listed in Table $\mathbf{1 .}$

\section{METHODS}

This protocol was approved by the Ottawa Health Science Research Ethics Board. All subjects gave written informed consent in accordance with the Declaration of Helsinki. Eligible

TABLE 1 | Antibodies used in whole blood panels.

\begin{tabular}{|c|c|c|c|}
\hline Antibody & Vendor & Cat \# & Clone \\
\hline CD3 FITC (mouse) & Invitrogen & $11-0039-41$ & HIT3a \\
\hline CD56 BV421 (mouse) & BD biosciences & 562751 & NCAM16.2 \\
\hline CD16 BV650 (mouse) & BD biosciences & 563692 & 3G8 \\
\hline CD14 APC-Cy7 (mouse) & BD biosciences & 557831 & MфP9 \\
\hline CD45 AF700 (mouse) & BD biosciences & 560566 & HI30 \\
\hline Fixable viability dye BV510 & BD biosciences & 564406 & - \\
\hline IFN $\gamma$ APC (mouse) & Invitrogen & 17-7319-82 & 4S.B3 \\
\hline CD25 PE-Cy7 (mouse) & BD biosciences & 557741 & M-A251 \\
\hline CD122 PE (mouse) & BD biosciences & 554522 & Mik- $\beta 2$ \\
\hline CD132 APC (rat) & Biolegend & 338607 & TUGh4 \\
\hline $\begin{array}{l}\text { p-STAT5 PE-Cy7 (pY694) } \\
\text { (mouse) }\end{array}$ & BD biosciences & 560117 & 47/Stat5 \\
\hline CD212 BV786 (mouse) & BD biosciences & 744207 & 2.4E6 \\
\hline Mouse BV786 IgG1 & BD biosciences & 563330 & $\times 40$ \\
\hline p-STAT4 PE (pY693) (mouse) & BD biosciences & 558249 & 38/p-Stat4 \\
\hline NKG2D BV650 (mouse) & BD biosciences & 563408 & $1 \mathrm{D} 11$ \\
\hline NKG2A PE (mouse) & R\&D Systems & FAB1059P-025 & 131411 \\
\hline BV786 TIM-3 (mouse) & BD biosciences & 742857 & 7D3 \\
\hline PE-Cy7 DNAM-1 (mouse) & BioLegend & 338315 & $11 \mathrm{~A} 8$ \\
\hline APC TIGIT (mouse) & BioLegend & 372705 & A15153G \\
\hline PD-1 PerCP-Cy5.5 (mouse) & BioLegend & 329913 & $\mathrm{EH} 12.2 \mathrm{H} 7$ \\
\hline S6 PE (pS235/236) (mouse) & BD biosciences & 560433 & NF-548 \\
\hline $\begin{array}{l}\text { p38 MAPK APC (pThr180, } \\
\text { Tyr 182) (mouse) }\end{array}$ & Invitrogen & $17-9078-42$ & 4NIT4KK \\
\hline Mouse PE IgG2a & BioLegend & 400214 & MOPC-173 \\
\hline Mouse APC IgG2A & BioLegend & 400219 & MOPC-173 \\
\hline Mouse PerCP-Cy5.5 lgG1 & BioLegend & 400149 & MOPC-21 \\
\hline Mouse APC IgG1 & Biolegend & 400119 & MOPC-21 \\
\hline Mouse PE-Cy7 IgG1 & BD biosciences & 557872 & MOPC-21 \\
\hline Mouse PE IgG2b & Invitrogen & $12-4732-41$ & eBMG2b \\
\hline Mouse BV650 lgG1 & BD biosciences & 563231 & $\times 40$ \\
\hline Rat APC IgG2b & Biolegend & 400611 & RTK4530 \\
\hline
\end{tabular}

patients were $>18$ years of age and had a planned surgical resection of the primary or metastatic tumor (cancer patients) or healthy donors who volunteered to participate. Exclusion criteria included a history of active viral or bacterial infection or known HIV or Hepatitis B or C, autoimmune diseases, or use of immunosuppressive medications.

\section{Protocol 1-Extracellular Receptor Staining (Supplementary Material; Figure 1A)}

Objective: Assess cell surface receptor expression in Natural Killer cells from whole blood.

Blood was collected from healthy donors and cancer surgery patients at baseline and on POD1. Two hundred microliters of whole blood was aliquoted per flow cytometry panel into a $15 \mathrm{~mL}$ conical tube. Forty microliters of extracellular staining (ECS) mix was added and mixed by pipetting. Blood was incubated for $15 \mathrm{~min}$ at room temperature (RT) prior to adding $4 \mathrm{~mL}$ of $\mathrm{BD}$ FACS lyse/fix buffer (BD Cat \#558049; 1:5 dilution with $\mathrm{diH}_{2} \mathrm{O}$ ). Tube were shaken vigorously to ensure red blood cell (RBC) lysis. Tubes were incubated for $10 \mathrm{~min}$ in a $37^{\circ} \mathrm{C}$ water bath and centrifuged at $500 \mathrm{~g}$ for $8 \mathrm{~min}$. Supernatant was carefully aspirated, and the cell pellet was resuspended in $1 \mathrm{~mL}$ flow buffer (FB; $500 \mathrm{~mL}$ PBS, $2.5 \mathrm{~g}$ Bovine serum albumin, $1 \mathrm{~mL} 0.5 \mathrm{M}$ EDTA). Cells were centrifuged at $500 \mathrm{~g}$ for $5 \mathrm{~min}$ and supernatant aspirated prior to resuspending in $200 \mu \mathrm{L} 1 \%$ paraformaldehyde (PFA). Samples were stored at $4{ }^{\circ} \mathrm{C}$ for up to $72 \mathrm{~h}$ prior to acquisition and analysis by flow cytometry. At least 2,500 events were collected, gating on $\mathrm{CD} 56^{+} \mathrm{CD} 3^{-} \mathrm{NK}$ cells.

\section{Protocol 2-Intracellular Signaling Protein Phosphorylation Staining (Supplementary Material; Figure 4A)}

Objective: Assess signaling protein/ transcription factor phosphorylation in response to stimuli in Natural Killer cells from whole blood.

Blood was collected from healthy donors and cancer surgery patients at baseline and on POD1. Five hundred microliters of whole blood was aliquoted per flow cytometry panel into a new sodium-heparin tube. Control (PBS) or IL-2/12 stimulation (400 $\mathrm{U} / 20 \mathrm{ng} / \mathrm{mL}$ ) and $40 \mu \mathrm{L}$ of ECS mix was added and mixed by pipetting. Blood was incubated for $20 \mathrm{~min}$ in a $37^{\circ} \mathrm{C}$ water bath and then transferred to a $15 \mathrm{~mL}$ conical tube prior to adding $10 \mathrm{~mL}$ of BD FACS lyse/fix buffer (1:5 dilution with $\mathrm{diH}_{2} \mathrm{O}$ ). Tubes were shaken vigorously to ensure RBC lysis. Tubes were incubated for $10 \mathrm{~min}$ in a $37^{\circ} \mathrm{C}$ water bath and centrifuged at $500 \mathrm{~g}$ for $8 \mathrm{~min}$. Supernatant was carefully aspirated, and the cell pellet was resuspended in $1 \mathrm{~mL}$ FB. Cells were centrifuged at $500 \mathrm{~g}$ for $5 \mathrm{~min}$ and supernatant was aspirated prior to resuspending in $500 \mu \mathrm{L}$ chilled BD Perm III buffer. Cells were incubated on ice in the dark for $30 \mathrm{~min}$ and centrifuged at $300 \mathrm{~g}$ for $10 \mathrm{~min}$. Supernatant was aspirated and the pellet was resuspended in 400 $\mu \mathrm{L} F B ; 200 \mu \mathrm{L}$ per well was then transferred into a 96 well vbottom plate and centrifuged at $500 \mathrm{~g}$ for $5 \mathrm{~min}$. The plate was decanted, and cells were resuspended in $200 \mu \mathrm{L}$ of appropriate intracellular staining (ICS) mix and incubated at RT in the dark 


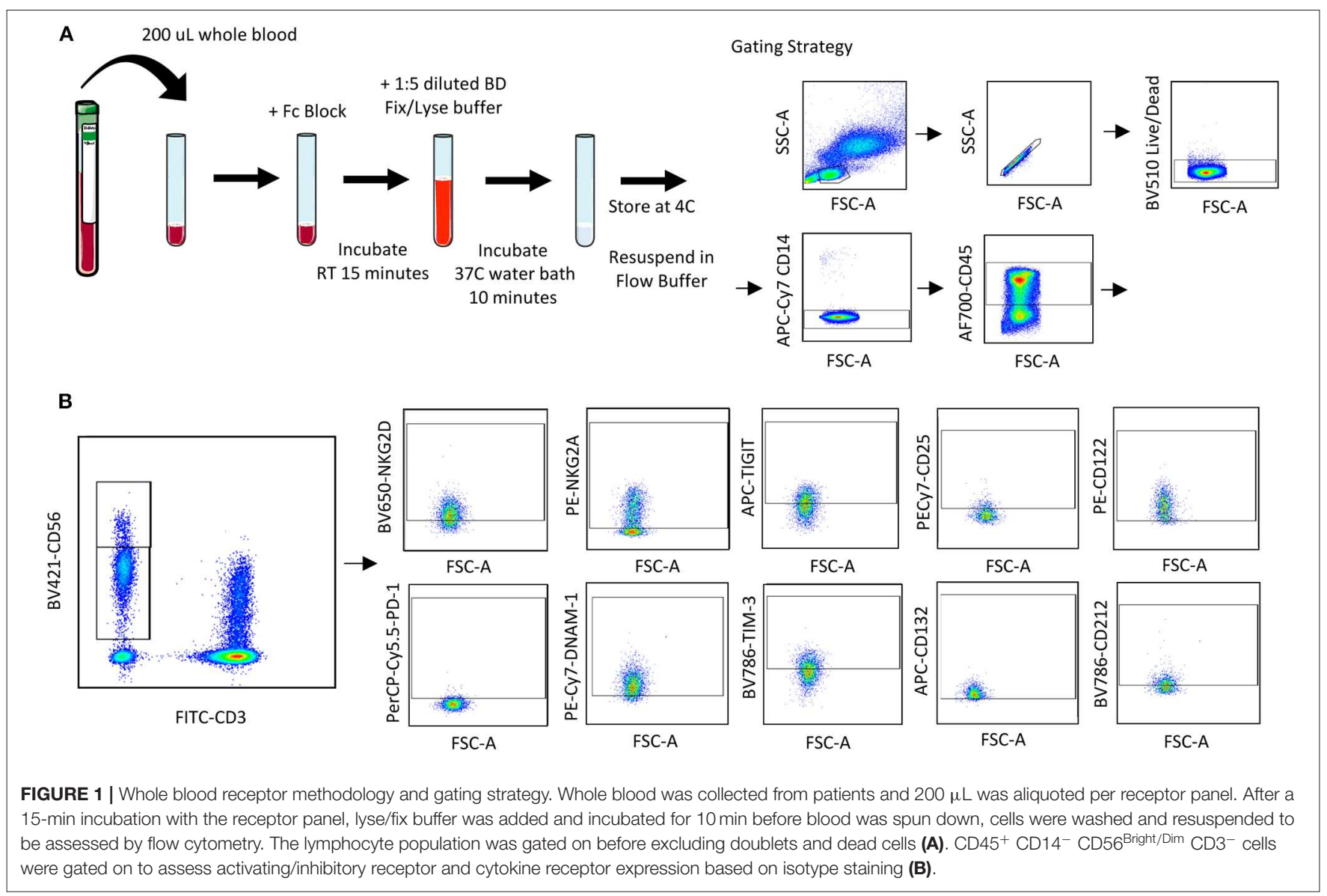

for $1 \mathrm{~h}$. The plate was spun at $500 \mathrm{~g}$ for $5 \mathrm{~min}$ and cells were resuspended in $1 \%$ PFA. Samples were stored at $4{ }^{\circ} \mathrm{C}$ for up to $72 \mathrm{~h}$ prior to acquisition and analysis by flow cytometry. At least 2, 500 events were collected, gating on $\mathrm{CD} 56^{+} \mathrm{CD} 3^{-} \mathrm{NK}$ cells.

\section{Protocol 3-Intracellular IFN $\gamma$ Staining (Supplementary Material; Figure 5A)}

Objective: Quantify intracellular IFN $\gamma$ production as a measure of activity in Natural Killer cells from whole blood.

Blood was collected from healthy donors and cancer surgery patients at baseline and on POD1. One milliliter of whole blood was aliquoted per flow cytometry panel into a new sodiumheparin tube. Whole blood was incubated with PBS (control) or PMA-ionomycin (50 ng/750 ng/mL) for $5 \mathrm{~h}$ or IL-2/12 (400 $\mathrm{U} / 20 \mathrm{ng} / \mathrm{mL}$ ) for $24 \mathrm{~h}$ at $37^{\circ} \mathrm{C} .10 \mu \mathrm{g} / \mathrm{mL}$ Golgiplug (Brefaldin A) per tube was added, tubes were inverted 10 times to mix, and incubated at $37^{\circ} \mathrm{C}$ for the remaining $2 \mathrm{~h}$ of each incubation. Six hundred microliter of whole blood was then collected in an Eppendorf tube, centrifuged at $500 \mathrm{~g} 5 \mathrm{~min}$, and plasma was collected and stored at $-80^{\circ} \mathrm{C}$ for an IFN $\gamma$ ELISA. The remaining $400 \mu \mathrm{L}$ of whole blood was transferred to a new $15 \mathrm{~mL}$ conical tube and incubated with Fc block (Human Trustain; Biolegend Cat \#422302) for $5 \mathrm{~min}$ at RT. The ECS mix was then added and mixed by pipetting. Blood was incubated for $15 \mathrm{~min}$ at RT prior to adding $20 \mathrm{~mL}$ of BD FACS lyse/fix buffer (1:5 dilution with
$\mathrm{diH}_{2} \mathrm{O}$ ). Tube were shaken vigorously to ensure $\mathrm{RBC}$ lysis. Tubes were incubated for $10 \mathrm{~min}$ in a $37^{\circ} \mathrm{C}$ water bath and centrifuged at $500 \mathrm{~g}$ for $8 \mathrm{~min}$. Supernatant was carefully aspirated, and the cell pellet was resuspended in $1 \mathrm{~mL} \mathrm{FB}$. Cells were centrifuged at $500 \mathrm{~g}$ for $5 \mathrm{~min}$ and supernatant was aspirated prior to resuspending in $500 \mu \mathrm{L}$ chilled BD Perm III buffer (BD Cat \#558050). Cells were incubated on ice in the dark for $30 \mathrm{~min}$ and centrifuged at $300 \mathrm{~g}$ for $10 \mathrm{~min}$. Supernatant was aspirated and the pellet was resuspended in $400 \mu \mathrm{L} \mathrm{FB;} 200 \mu \mathrm{L}$ per well was then transferred into a 96-well v-bottom plate and centrifuged at $500 \mathrm{~g}$ for $5 \mathrm{~min}$. The plate was decanted, and cells were resuspended in $200 \mu \mathrm{L}$ of appropriate ICS mix and incubated at $4{ }^{\circ} \mathrm{C}$ for $30 \mathrm{~min}$ in the dark for $1 \mathrm{~h}$. The plate was spun at $500 \mathrm{~g}$ for $5 \mathrm{~min}$ and cells were resuspended in $1 \%$ PFA. Samples were stored at $4^{\circ} \mathrm{C}$ for up to $72 \mathrm{~h}$ prior to acquisition and analysis by flow cytometry. At least 2, 500 events were collected, gating on $\mathrm{CD}_{5} 6^{+} \mathrm{CD} 3^{-}$ NK cells.

\section{Extracellular IFN $\gamma$ Quantification (Supplementary Material; Figure 6A)}

Objective: Quantify extracellular IFN $\gamma$ production as a measure of activity in plasma from whole blood.

The R\&D Quantikine ${ }^{\circledR}$ ELISA Human IFN $\gamma$ Immunoassay (Cat \#DIF50) was used to quantify extracellular IFN $\gamma$ from cell culture supernatant and patient plasma. Samples were thawed 
at RT and either run undiluted or at a dilution of $5 \mathrm{x}$ or $10 \mathrm{x}$ with appropriate buffer. This assay was run following the R\&D Quantikine ${ }^{\circledR}$ ELISA protocol. The minimum detectable dose (MDD) for the assay is $<8.0 \mathrm{pg} / \mathrm{mL}$.

\section{DATA ANALYSIS}

Descriptive statistics were used to summarize data collected on extracellular receptors, phospho-signaling proteins, and IFN $\gamma$ production [median with interquartile range (IQR)]. Wilcoxon matched-pairs signed rank test was used to determine if there were significant changes in receptor expression (percentage and MFI) between cryopreserved and whole blood samples. The level for statistical significance was set a priori at $\leq 0.05\left({ }^{*} p \leq 0.05\right.$, ${ }^{* *} p$ $\left.\leq 0.005,{ }^{* * *} p \leq 0.0005,{ }^{* * * *} p \leq 0.00005\right)$. All statistical analyses were performed using Prism 8.

\section{RESULTS}

\section{Protocol 1-Extracellular Receptor Staining Quantifying NK Cell Surface Receptors in Whole Blood}

Using a 10 color flow cytometry panel, we assessed the surface expression of six NK cell receptors, which are known to activate

TABLE 2 | Whole blood patient demographics.

\begin{tabular}{|c|c|c|c|}
\hline Category & Subcategory & Healthy donors & Patients \\
\hline Total (n) & & 40 & 39 \\
\hline \multirow[t]{2}{*}{ Sex } & Male & 16 & 21 \\
\hline & Female & 24 & 18 \\
\hline \multirow[t]{3}{*}{ Patient age } & $<60$ years & 24 & 11 \\
\hline & 60-69 years & 9 & 19 \\
\hline & >70 years & 7 & 9 \\
\hline \multirow[t]{12}{*}{ Cancer type } & Prostate & - & 11 \\
\hline & Lung & - & 7 \\
\hline & Colorectal & - & 6 \\
\hline & Renal & - & 3 \\
\hline & Ovarian & - & 3 \\
\hline & Sarcoma & - & 3 \\
\hline & Pancreatic & - & 1 \\
\hline & Parathyroid & - & 1 \\
\hline & Neuroendocrine & - & 1 \\
\hline & Endometrial & - & 1 \\
\hline & Duodenal & - & 1 \\
\hline & Uterine & - & 1 \\
\hline \multirow[t]{4}{*}{ Staging } & 1 & - & 14 \\
\hline & $\|$ & - & 7 \\
\hline & III & - & 15 \\
\hline & IV & - & 3 \\
\hline
\end{tabular}

Summary of patient information including sex, age, cancer type, and cancer staging for patient samples used to quantify receptor expression, phosphorylation status, and IFN $\gamma$ production using whole blood.
(NKG2D and DNAM-1) or inhibit (NKG2A, PD-1, TIGIT, and TIM-3) NK cell effector functions in a cohort of 16 healthy donors and 20 cancer patients (Table 2). Using a nine color flow cytometry panel, we similarly assessed whether the expression of IL-2/12 receptor subunits [CD25 ( $\alpha)$, CD122 ( $\beta)$, CD132 $(\gamma)$, and $\operatorname{CD} 212(\beta 1)]$ could be detected in 13 healthy donors and 11 cancer patients (Table 2). We assessed the percentage of positive cells as well as the relative expression level (median fluorescence intensity/MFI) of both activating/inhibitory and cytokine receptors in $\mathrm{CD} 56^{\text {Bright }} \mathrm{CD} 3^{-}$and $\mathrm{CD} 56^{\text {Dim }} \mathrm{CD} 3^{-} \mathrm{NK}$ cells using the indicated gating strategy (Figure 1). Gates were set based on matched isotype controls (Supplementary Figure 1). We were able to assess both activating/inhibitory and cytokine receptor expression using this whole blood protocol (Figure 2 and Supplementary Table 1 ).

\section{Discrepancies Between Whole Blood and Cryopreserved NK Cell Surface Receptors}

In addition to whole blood we also assessed the expression of NKG2D, DNAM-1, PD-1, TIGIT, and TIM-3 $(n=10)$ and CD25 and CD212 $(n=14)$ in NK cells from cryopreserved PBMCs (Table 3). After Ficoll density centrifugation, PBMCs were isolated, washed, and stored in liquid nitrogen in 90\% FBS $10 \%$ DMSO. We followed a standard protocol whereby PBMCs were thawed, rested overnight, and stained using a 10 color (activating/inhibitory receptors) or a nine color (cytokine receptors) flow cytometry panel (29-32) PBMC viability and yield after thawing were $\geq 73$ and $\geq 50 \%$, respectively. At least 2,500 events were collected, gating on $\mathrm{CD}_{5}{ }^{+} \mathrm{CD} 3^{-} \mathrm{NK}$ cells (gating strategy shown in Supplementary Figure 2). Consistent with previous publications, we found significant differences between the percentage of positive cells and receptor MFI in

TABLE 3 | Cryopreserved PBMC patient demographics.

\begin{tabular}{llc}
\hline Category & Subcategory & Patients \\
\hline Total $(n)$ & & 19 \\
Gender & Male & 13 \\
& Female & 6 \\
Patient Age & $<60$ years & 5 \\
& 60-69 years & 9 \\
Cancer Type & $>70$ years & 5 \\
& Prostate & 8 \\
& Lung & 8 \\
Staging & Colorectal & 2 \\
& Esophageal & 1 \\
& I & 4 \\
& II & 5 \\
& III & 7 \\
& IV & 2 \\
& Unknown & 1
\end{tabular}

Summary of patient information including sex, age, cancer type, and cancer staging for patient samples used to quantify activating/inhibitory/cytokine receptors using cryopreserved PBMCs. 


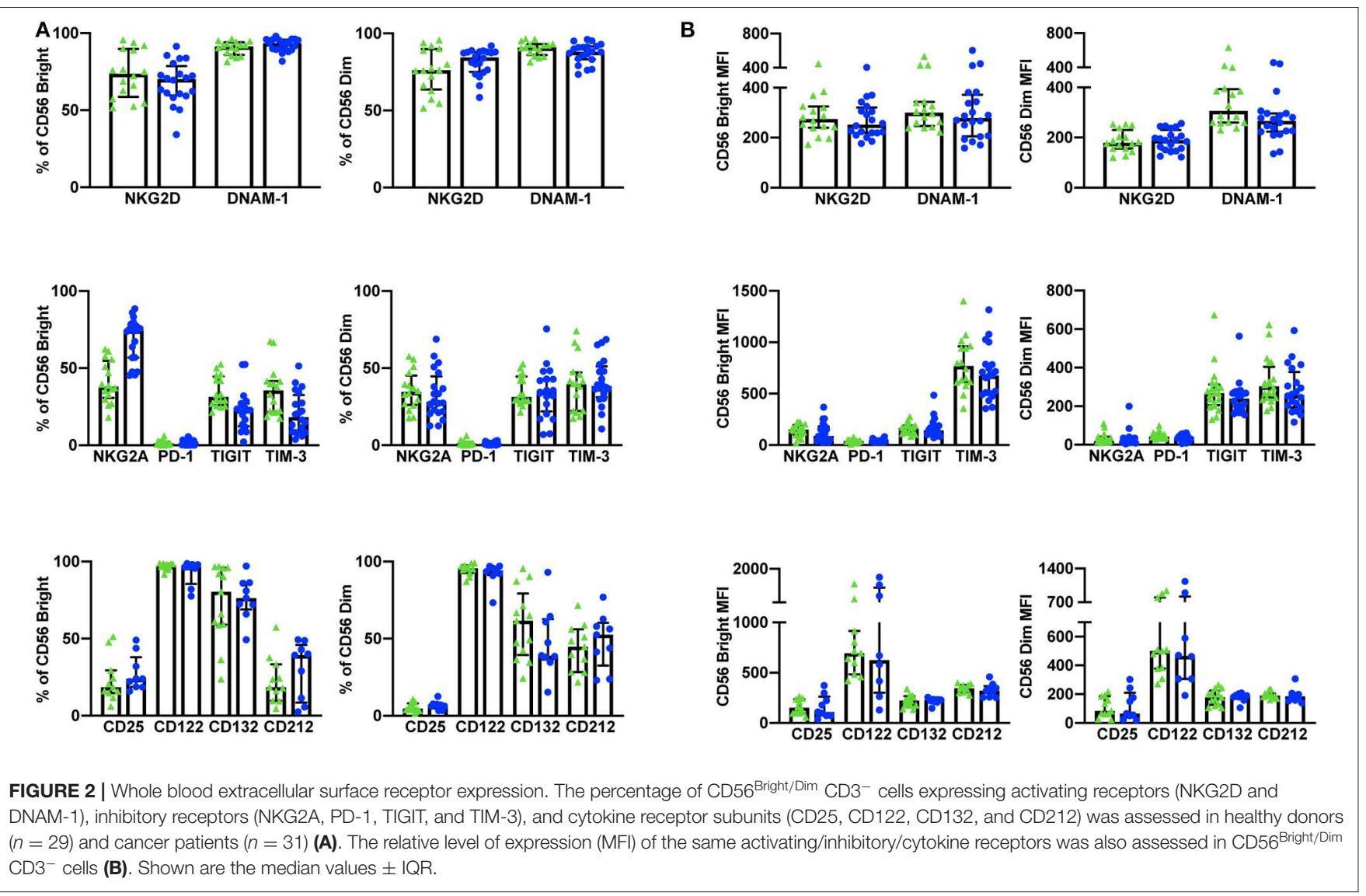

cryopreserved vs. whole blood NK cells $(33,34)$ (Figure 3, Supplementary Table 2).

\section{Protocol 2-Intracellular Signaling Protein Phosphorylation Staining}

Detecting NK Cell Cytokine Signaling in Whole Blood

The phosphorylation of signaling proteins downstream of IL2/12 receptors was assessed using two 7 color flow cytometry panels in 13 healthy donors and nine cancer patients. Phosphospecific antibodies against STAT5, STAT4, p38 MAPK, and S6 were used to determine the relative phosphorylation of (MFI) the relative phosphorylation (MFI) in $\mathrm{CD} 56^{\text {Bright }} \mathrm{CD}^{-}$and $\mathrm{CD}^{2}{ }^{\mathrm{Dim}} \mathrm{CD}^{-}{ }^{-} \mathrm{NK}$ cells (Figure 4B). We were able to quantify the phosphorylation of these signaling molecules in response to IL-2/12 stimulation in both healthy donors and cancer patients (Figure 4C, Supplementary Table 3).

\section{Protocol 3-Intracellular IFN $\gamma$ Staining Quantifying NK Cell Responsiveness to Cytokine Stimulation}

Finally, NK cell activity was quantified by measuring both intracellular and extracellular IFN $\gamma$ production in response to stimulation with either PMA-ionomycin (a receptorindependent stimulator of cytokine production) or IL-2/12. A six color flow cytometry panel and the indicated gating strategy was used to assess the percentage of $\mathrm{CD} 56^{\mathrm{Bright}} \mathrm{CD}^{-}$and
CD56 ${ }^{\text {Dim }}{ }^{-} \mathrm{CD} 3^{-}$NK cells producing IFN $\gamma$ in 11 healthy donors and nine cancer patients (Figure 5A). Gates were set based on matched unstimulated controls (Supplementary Figure 1). The healthy donor and cancer patient populations produced intracellular IFN $\gamma$ in response to both stimuli (Figure 5B, Supplementary Table 4). In addition, extracellular IFN $\gamma$ was quantified in 13 healthy donors and 10 cancer patients from plasma collected prior to intracellular staining (Figure 6B, Supplementary Table 4).

Next, we investigated whether increased IFN $\gamma$ production could be correlated with phosphorylation of upstream signaling proteins. Since STAT4 is phosphorylated in response to IL12 receptor binding and contributes to IFN $\gamma$ production we investigated the correlation of pSTAT4 MFI and IFN $\gamma$ MFI in $\mathrm{CD}_{5} 6^{\text {Bright }}$ and $\mathrm{CD} 56^{\text {Dim }}$ NK cells. Notably, we observed a moderate correlation between pSTAT4 and IFN $\gamma$ MFI in both $\mathrm{CD}_{5} 6^{\text {Bright }}\left(R^{2}=0.2819, p<0.05\right)$ and CD56 ${ }^{\text {Dim }}\left(R^{2}=0.2148, p<0.05\right)$ populations, suggesting that upstream phosphorylation events are correlated with cytokine production despite differences in sample preparation (Supplementary Figure 3). The strength of this relationship may be impacted by the heterogeneity of patient samples as well as the small patient population being assessed. However, similar relationships have been reported in the literature to support causal relationships in assessing lymphocyte dysfunction (35). 

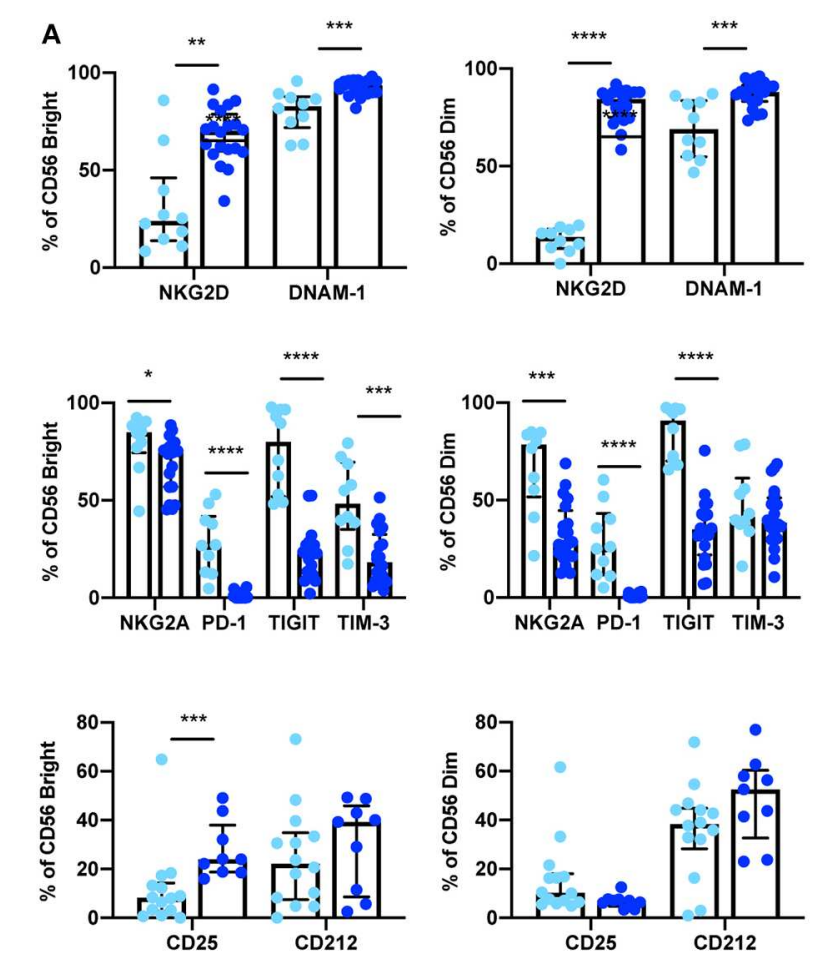

B
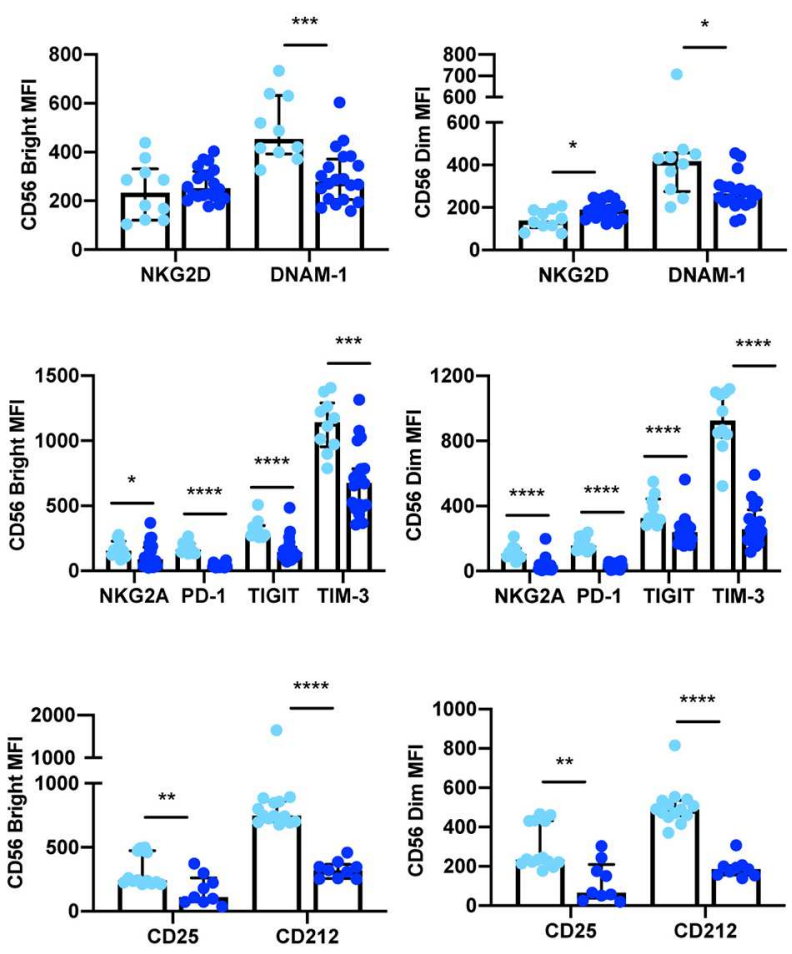

FIGURE 3 | Expression of extracellular surface receptors differs between cryopreserved PBMCs and whole blood samples. A significant difference was observed between the percentage of CD56 ${ }^{\text {Bright/Dim }} \mathrm{CD}^{-}$cells expressing all activating and inhibitory receptors (cryopreserved $n=10$, whole blood $n=20$ ), as well as the cytokine receptor subunits CD25 and CD212 (cryopreserved $n=14$, whole blood $n=11$ ) (A). In addition, a significant difference was also observed in the relative expression levels (MFI) of these receptors in both CD56 ${ }^{\text {Bright }}$ and CD56 ${ }^{\text {Dim }}$ populations (B). Shown are the median values \pm IQR. The Mann-Whitney test was used to assess statistical significance. $p \leq 0.05\left({ }^{\star} p \leq 0.05,{ }^{* *} p \leq 0.005,{ }^{* \star *} p \leq 0.0005,{ }^{\star \star * *} p \leq 0.00005\right)$.

Granulocytes are large lymphocytes that contain cytoplasmic granules and include neutrophils, basophils, and eosinophils, with neutrophils being the most abundant leukocyte in human blood (36). Neutrophils have been shown to have pleotropic effects on NK cells ranging from inducing NK cell licensing to inhibiting proliferation and IFN $\gamma$ production, to enhancing cytotoxic activity $(37,38)$. The Ficoll separation of PBMCs allows for the removal of higher density neutrophils. However, in using whole blood for phenotypic and functional assays granulocytes are present at biologically relevant concentrations. In order to discern whether these cells were having an impact on $\mathrm{NK}$ cell cytokine production, we quantified the percentage of $\mathrm{CD}^{-} 4^{-}$FSC-A ${ }^{\text {hi }}$ SSC-A ${ }^{\text {hi }}$ cells and plotted this against intracellular IFN $\gamma$ in the same 11 healthy donors and nine cancer patients. We did not find a correlation between the two, suggesting that in these whole blood protocols, IFN $\gamma$ production is not influenced by the presence of granulocytes (Supplementary Figure 4).

\section{ADVANTAGES}

These assays require minimal volumes of blood $(200 \mu \mathrm{L}-1 \mathrm{~mL}$ per sample) as compared to methods employing cryopreserved PBMCs $(\sim 30-40 \mathrm{~mL})$. This allows for the simultaneous assessment of many targets and the use of whole blood from one patient for multiple assays. In addition, patients may be more likely to consent to blood draws for research that requires minimal blood volumes. These assays can be used to effectively measure extracellular and intracellular targets in healthy as well as disease states (cancer). Here we have assessed $\mathrm{CD}_{56}{ }^{\text {Bright }} \mathrm{CD}^{-}$and $\mathrm{CD}^{-} 6^{\text {Dim }} \mathrm{CD}^{-}$NK cell phenotype and function; however, the use of whole blood allows for the assessment of any immune cell, including neutrophils which would otherwise the excluded in PBMC isolation protocols. Finally, a discrepancy can be seen between extracellular targets measured on NK cells using whole blood vs. cryopreserved PBMCs. We believe that assessing immune cell phenotypes using whole blood may be more biologically relevant as these protocols minimize the time between blood draw and cell staining and reduce the manipulation of cells that may otherwise impact target expression.

\section{LIMITATIONS}

Although the protocol described in this paper features several technical and scientific advantages, it is important to note the potential limitations. However, through the use of appropriate controls (unstained, isotype, fluorescence minus one, "healthy donors"), operator training, validation of standard operating procedures, and equipment calibration the potential impact 


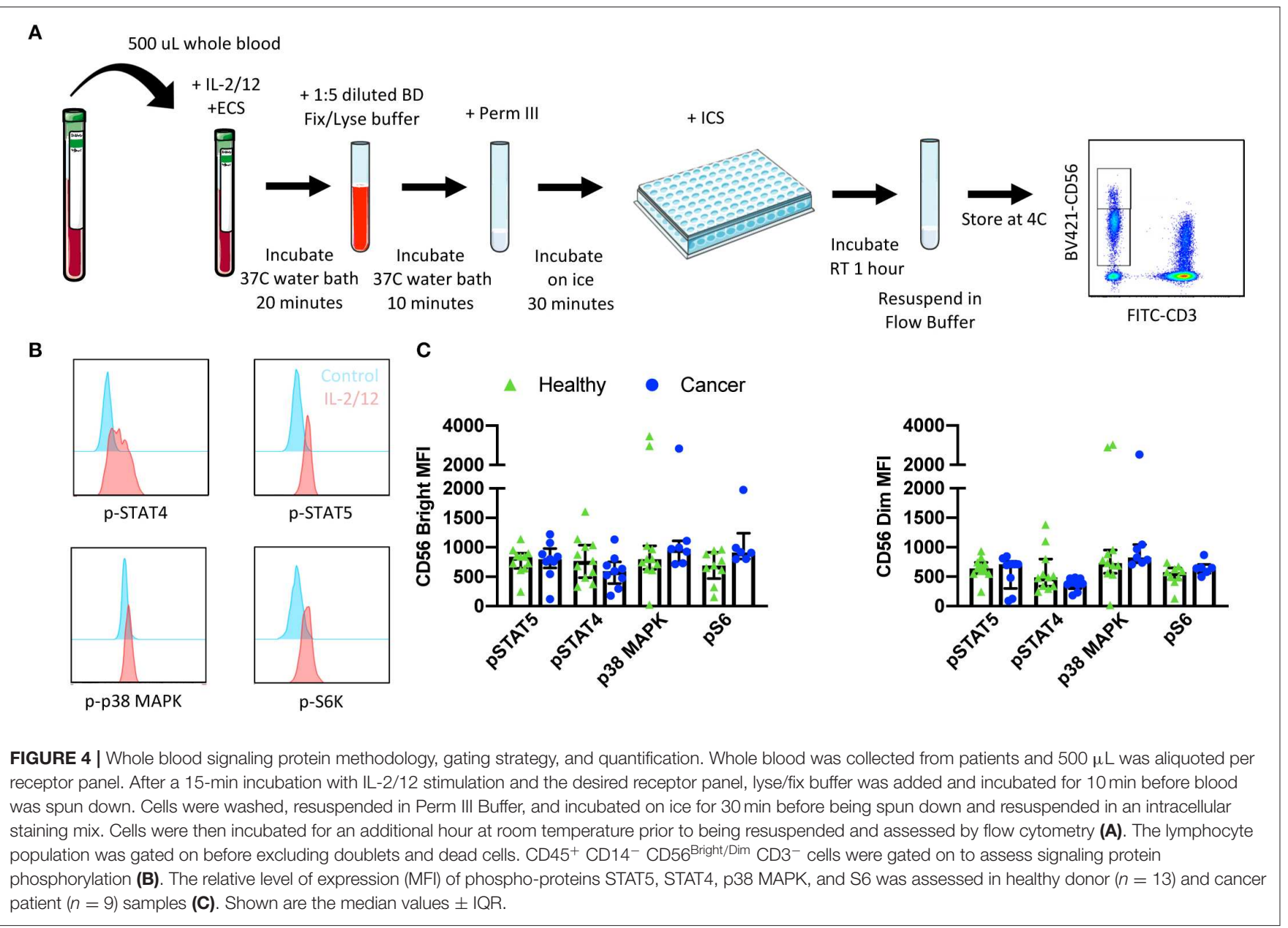

on inter-assay variability inherent to longitudinal studies using whole blood samples can be reduced. In addition, additional cell surface markers may be required to fully explore the impact of the inherent biological variation in the relative frequency of immune cell populations in functional assays using whole blood samples. For example, granulocyte populations present in relatively high frequencies in whole blood are absent in isolated PBMCs. Although we did not observe a correlation between granulocyte frequency and NK cell function (IFN $\gamma$ ) in our patient samples, the activation of the large and variable number of granulocytes present in whole blood samples may impact results depending on the immunological phenotypes and target cell populations of interest.

\section{TROUBLESHOOTING}

Antibodies need to be titrated using whole blood protocols to ensure appropriate staining. Stimulation incubation times may have to be adjusted for different signaling proteins depending on the target (15-30 min is a good range to test). Mix FACS lyse/fix buffer and blood vigorously to ensure lysis of RBCs; if RBCs are left in the pellet the lyse/fix step can be repeated a second time. Golgiplug (Brefaldin A) may be added with 4 vs. $2 \mathrm{~h}$ of incubation time remaining to quantify intracellular cytokine production. Intracellular staining can be done in falcon tubes instead of a 96-well v-bottom plate, but the pellet is easier to visualize in a plate. Samples can be resuspended in flow buffer for up to $24 \mathrm{~h}$ or $1 \%$ PFA for longer storage at $4{ }^{\circ} \mathrm{C}$. CD45 and CD14 staining are not necessary but make gating on the $\mathrm{CD} 56^{+}$ $\mathrm{CD}^{-}$population cleaner.

\section{DISCUSSION}

The workflow of some immune cell studies may be more compatible with protocols utilizing cryopreserved samples, for example multi-institute studies, however, due to the advantages reported here we suggest that some assays may be significantly improved through the implementation of whole blood protocols. These assays circumvent the limitations associated with the use of cryopreserved PBMCs, namely manipulation of cells and the thawing process which may alter cell phenotype and function. Consistent with previously reported differences between cryopreserved and whole blood PBMC assays, we show that cryopreservation results in an aberrant NK cell phenotype $(24,33,34)$. We suggest that this discrepancy may lead to misinterpreted conclusions about altered immune cell phenotype 

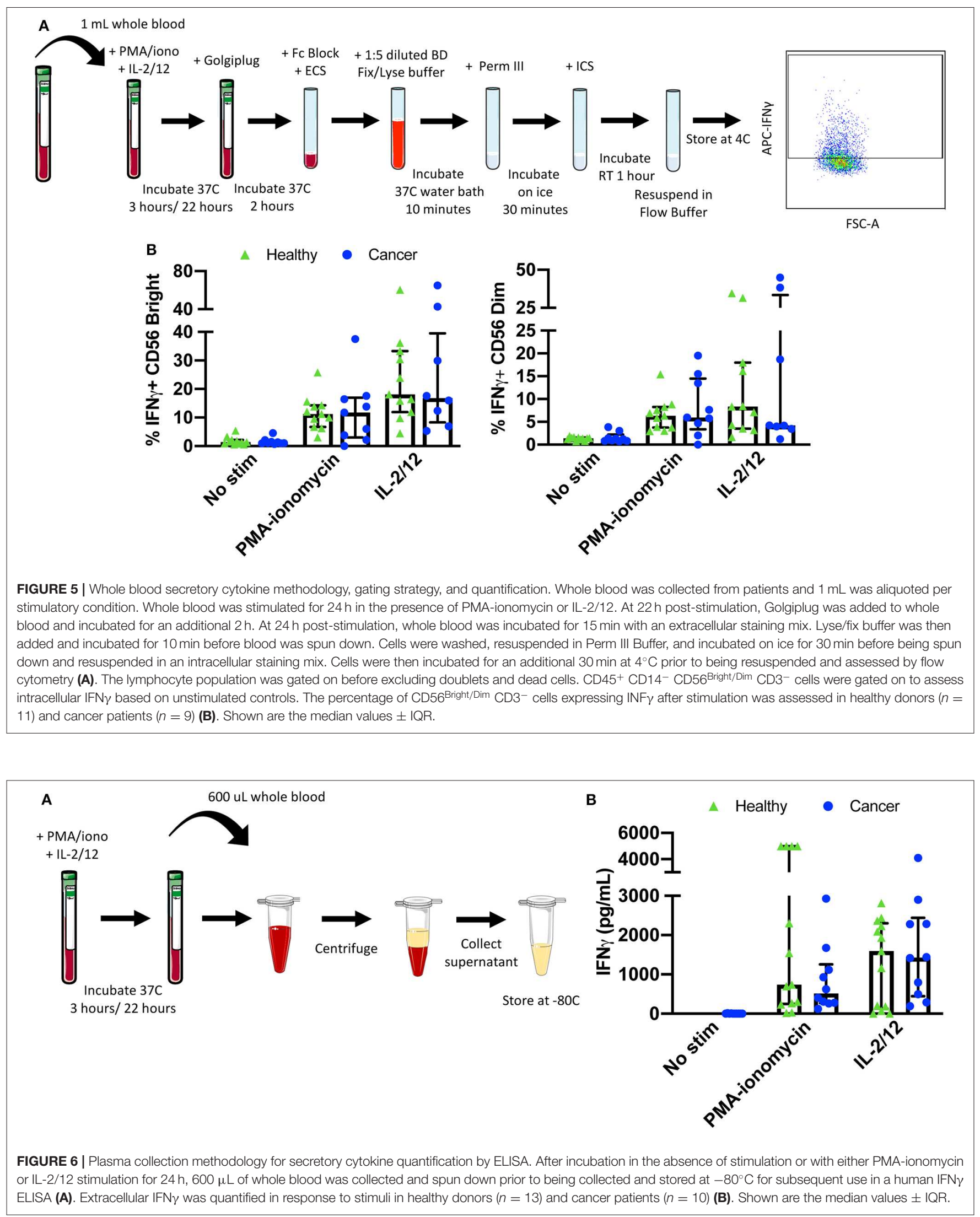
and function. As a possible solution, we present methodologies for parallel assessment of immune cell receptor expression, signaling protein activity, and cytokine production in whole blood-derived NK cells. We have demonstrated the feasibility of these assays through the detection of target protein expression in both healthy and disease states (namely solid malignancies), the reproducibility of these assays in patient cohorts despite inherent inter-patient heterogeneity, and the validity of these assays in that our results are comparable to those previously described in the literature $(2,12,32,34,39-44)$. They are simple, time-efficient, and allow for the assessment of any peripheral immune cell population using a minimal volume of whole blood. Finally, we suggest that they could be used to assess immune cell phenotype and function in any pathological condition, provided sufficient blood volumes.

\section{DATA AVAILABILITY STATEMENT}

The datasets for this study can be made available upon reasonable request.

\section{ETHICS STATEMENT}

The studies involving human participants were reviewed and approved by Ottawa Health Science Research Ethics Board. The

\section{REFERENCES}

1. Kiessling R, Klein E, Pross H, Wigzell H. "Natural" killer cells in the mouse. II. Cytotoxic cells with specificity for mouse Moloney leukemia cells. Characteristics of the killer cell. Eur J Immunol. (1975) 5:11721. doi: 10.1002/eji.1830050209

2. Angka L, Martel AB, Kilgour M, Jeong A, Sadiq M, de Souza CT, et al. Natural killer cell IFN $\gamma$ secretion is profoundly suppressed following colorectal cancer surgery. Ann Surg Oncol. (2018) 25:3747-54. doi: 10.1245/s10434-018-6691-3

3. Weinberg A, Song LY, Wilkening C, Sevin A, Blais B, Louzao R, et al. Optimization and limitations of use of cryopreserved peripheral blood mononuclear cells for functional and phenotypic T-cell characterization. Clin Vaccine Immunol. (2009) 16:1176-86. doi: 10.1128/CVI.00342-08

4. Zhang W, Nilles TL, Johnson JR, Margolick JB. The effect of cellular isolation and cryopreservation on the expression of markers identifying subsets of regulatory $\mathrm{T}$ cells. J Immunol Methods. (2016) 431:317. doi: 10.1016/j.jim.2016.02.004

5. Ruitenberg JJ, Mulder CB, Maino VC, Landay AL, Ghanekar SA. VACUTAINER ${ }^{\circledR} \quad \mathrm{CPT}^{\mathrm{TM}}$ and Ficoll density gradient separation perform equivalently in maintaining the quality and function of PBMC from HIV seropositive blood samples. BMC Immunol. (2006) 7:11. doi: 10.1186/1471-2172-7-11

6. Yang J, Diaz N, Adelsberger J, Zhou X, Stevens R, Rupert A, et al. The effects of storage temperature on PBMC gene expression. BMC Immunol. (2016) 17:6. doi: 10.1186/s12865-016-0144-1

7. Paust S, Senman B, Von Andrian UH. Adaptive immune responses mediated by natural killer cells. Immunol Rev. (2010) 235:286-96. doi: 10.1111/j.0105-2896.2010.00906.x

8. Long EO, Sik Kim H, Liu D, Peterson ME, Rajagopalan S. Controlling natural killer cell responses: integration of signals for activation and inhibition. Annu Rev Immunol. (2013) 31:227-58. doi: 10.1146/annurev-immunol-020711-075005

9. Jonjić S, Babić M, Polić B, Krmpotić A. Immune evasion of natural killer cells by viruses. Curr Opin Immunol. (2008) 20:30-8. doi: 10.1016/j.coi.2007.11.002 patients/participants provided their written informed consent to participate in this study.

\section{AUTHOR CONTRIBUTIONS}

MM and GT performed the experiments and data analysis and were responsible for manuscript preparation. JN and MS screened and consented all patients and performed blood processing on cryopreserved samples. MM, GT, CS, MK, and RA oversaw experimental design and data interpretation.

\section{FUNDING}

The authors received funding from the following agencies: Cancer Research Society, Terry Fox Foundation (\#1073), Canadian Institute of Healthy Research, Ontario Graduate Scholarship, Queen Elizabeth II Graduate scholarship.

\section{SUPPLEMENTARY MATERIAL}

The Supplementary Material for this article can be found online at: https://www.frontiersin.org/articles/10.3389/fimmu. 2020.00963/full\#supplementary-material

10. Fogel LA, Yokoyama WM, French AR. Natural killer cells in human autoimmune disorders. Arthritis Res Ther. (2013) 15:216. doi: 10.1186/ar4232

11. Orange JS, Ballas ZK. Natural killer cells in human health and disease. Clin Immunol. (2006) 50:102-11. doi: 10.1016/j.clim.2005.10.011

12. Tai LH, Alkayyal AA, Leslie AL, Sahi S, Bennett S, Tanese de Souza C, et al. Phosphodiesterase- 5 inhibition reduces postoperative metastatic disease by targeting surgery-induced myeloid derived suppressor cell-dependent inhibition of Natural Killer cell cytotoxicity. Oncoimmunology. (2018) 7:e1431082. doi: 10.1080/2162402X.2018.1431082

13. Tai LH, De Souza CT, Bélanger S, Ly L, Alkayyal AA, Zhang J, et al. Preventing postoperative metastatic disease by inhibiting surgeryinduced dysfunction in natural killer cells. Cancer Res. (2013) 73:97107. doi: 10.1158/0008-5472.CAN-12-1993

14. Zhang S, Kaplan MH. The p38 mitogen-activated protein kinase is required for IL-12-induced IFN- expression. J Immunol. (2000) 165:137480. doi: 10.4049/jimmunol.165.3.1374

15. Chester C, Fritsch K, Kohrt HE. Natural killer cell immunomodulation: targeting activating, inhibitory, and co-stimulatory receptor signaling for cancer immunotherapy. Front Immunol. (2015) 6:601. doi: 10.3389/fimmu.2015.00601

16. Marçais A, Cherfils-Vicini J, Viant C, Degouve S, Viel S, Fenis A, et al. The metabolic checkpoint kinase mTOR is essential for IL-15 signaling during the development and activation of NK cells. Nat Immunol. (2014) 15:74957. doi: 10.1038/ni.2936

17. Kasahara T, Hooks JJ, Dougherty SF, Oppenheim JJ. Interleukin 2-mediated immune interferon (IFN-gamma) production by human $\mathrm{T}$ cells and $\mathrm{T}$ cell subsets. J Immunol. (1983) 130:1784-9.

18. Bachmann MF, Oxenius A. Interleukin 2: from immunostimulation to immunoregulation and back again. EMBO Rep. (2007) 8:1142-8. doi: 10.1038/sj.embor.7401099

19. Ouyang W, Jacobson NG, Bhattacharya D, Gorham JD, Fenoglio D, Sha WC, et al. The Ets transcription factor ERM is Th1-specific and induced by IL-12 through a Stat4-dependent pathway. Proc Natl Acad Sci USA. (1999) 96:3888-93. doi: 10.1073/pnas.96.7.3888 
20. Lazarevic V, Glimcher LH, Lord GM. T-bet: a bridge between innate and adaptive immunity. Nat Rev Immunol. (2013) 13:777-89. doi: 10.1038/ nri3536

21. Chan CJ, Smyth MJ, Martinet L. Molecular mechanisms of natural killer cell activation in response to cellular stress. Cell Death Differ. (2014) 21:514. doi: $10.1038 / \mathrm{cdd} .2013 .26$

22. Mavropoulos A, Sully G, Cope AP, Clark AR. Stabilization of IFN- $\gamma$ mRNA by MAPK p38 in IL-12- and IL-18-stimulated human NK cells. Blood. (2005) 105:282-8. doi: 10.1182/blood-2004-07-2782

23. Posevitz-Fejfár A, Posevitz V, Gross CC, Bhatia U, Kurth F, Schütte V, et al. Effects of blood transportation on human peripheral mononuclear cell yield, phenotype and function: implications for immune cell biobanking. PLOS ONE. (2014) 9:e115920. doi: 10.1371/journal.pone.0115920

24. Dominguez E, Lowdell MW, Perez-Cruz I, Madrigal A, Cohen SBA. Natural killer cell function is altered by freezing in DMSO. Biochem Soc Transac. (1997) 25:175S. doi: 10.1042/bst025175s

25. Mata MM, Mahmood F, Sowell RT, Baum LL. Effects of cryopreservation on effector cells for antibody dependent cell-mediated cytotoxicity (ADCC) and natural killer (NK) cell activity in 51Cr-release and CD107a assays. J Immunol Methods. (2014) 406:1-9. doi: 10.1016/j.jim.2014.01.017

26. Claus M, Greil J, Watzl C. Comprehensive analysis of NK cell function in whole blood samples. J Immunol Methods. (2009) 341:154-64. doi: 10.1016/j.jim.2008.11.006

27. Ebbo M, Gérard L, Carpentier S, Vély F, Cypowyj S, Farnarier C, et al. Low circulating natural killer cell counts are associated with severe disease in patients with common variable immunodeficiency. EBioMedicine. (2016) 6:222-30. doi: 10.1016/j.ebiom.2016.02.025

28. Domogala A, Alejandro Madrigal J, Saudemont A. Cryopreservation has no effect on function of natural killer cells differentiated in vitro from umbilical cord blood CD34+ cells. Cytotherapy. (2016) 18:7549. doi: 10.1016/j.jcyt.2016.02.008

29. Ramachandran H, Laux J, Moldovan I, Caspell R, Lehmann PV, Subbramanian RA. Optimal thawing of cryopreserved peripheral blood mononuclear cells for use in high-throughput human immune monitoring studies. Cells. (2012) 1:313-24. doi: 10.3390/cells1030313

30. Kutscher S, Dembek CJ, Deckert S, Russo C, Körber N, Bogner JR, et al. Overnight resting of PBMC changes functional signatures of antigen specific T- cell responses: impact for immune monitoring within clinical trials. PLoS ONE. (2013) 8:e76215. doi: 10.1371/journal.pone.0076215

31. Wang L, Hückelhoven A, Hong J, Jin N, Mani J, Chen B an, et al. Standardization of cryopreserved peripheral blood mononuclear cells through a resting process for clinical immunomonitoring-Development of an algorithm. Cytometry A. (2016) 89:246-58. doi: 10.1002/cyto.a. 22813

32. Dunne J, Lynch S, O’Farrelly C, Todryk S, Hegarty JE, Feighery C, et al. Selective expansion and partial activation of human NK cells and NK receptor-positive T cells by IL-2 and IL-15. J Immunol. (2001) 167:312938. doi: 10.4049/jimmunol.167.6.3129

33. Miralles A, Peiró M, Amill B, de Dalmases C, Piñol G, Rueda F, et al. Differential effect of cryopreservation on natural killer cell and lymphokine-activated killer cell activities. Transfusion. (1993) 33:6515. doi: 10.1046/j.1537-2995.1993.33893342746.x
34. Naranbhai V, Bartman P, Ndlovu D, Ramkalawon P, Ndung'u T, Wilson D, et al. Impact of blood processing variations on natural killer cell frequency, activation, chemokine receptor expression and function. J Immunol Methods. (2011) 366:28-35. doi: 10.1016/j.jim.2011.01.001

35. Sim GC, Wu S, Jin L, Hwu P, Radvanyi LG. Defective STAT1 activation associated with impaired IFN- $\eta$ production in NK and T lymphocytes from metastatic melanoma patients treated with IL-2. Oncotarget. (2016) 7:3607491. doi: 10.18632/oncotarget.8683

36. Schulze TJ, Bugert P. Granulocytes: from basic research to clinical use. Transfus Med Hemotherapy. (2018) 45:288-9. doi: 10.1159/000494035

37. Amano K, Hirayama M, Azuma E, Iwamoto S, Keida Y, Komada Y. Neutrophils induced licensing of natural killer cells. Mediators Inflamm. (2015) 2015:747680. doi: 10.1155/2015/747680

38. Costantini C, Cassatella MA. The defensive alliance between neutrophils and NK cells as a novel arm of innate immunity. J Leukoc Biol. (2011) 89:221-33. doi: 10.1189/jlb.0510250

39. Saito H, Osaki T, Ikeguchi M. Decreased NKG2D expression on NK cells correlates with impaired NK cell function in patients with gastric cancer. Gastric Cancer. (2012) 15:27-33. doi: 10.1007/s10120-0110059-8

40. Yin X, Liu T, Wang Z, Ma M, Lei J, Zhang Z, et al. Expression of the inhibitory receptor TIGIT is up-regulated specifically on NK cells with CD226 activating receptor from HIV-infected individuals. Front Immunol. (2018) 9:2341. doi: 10.3389/fimmu.2018.02341

41. Han B, Mao F, Zhao Y, Lv Y, Teng Y, Duan M, et al. Altered NKp30, NKp46, NKG2D, and DNAM-1 expression on circulating NK cells is associated with tumor progression in human gastric cancer. J Immunol Res. (2018) 2018:6248590. doi: 10.1155/2018/6248590

42. Hatton O, Strauss-Albee DM, Zhao NQ, Haggadone MD, Pelpola JS, Krams $\mathrm{SM}$, et al. NKG2A-expressing natural killer cells dominate the response to autologous lymphoblastoid cells infected with epstein-barr virus. Front Immunol. (2016) 7:607. doi: 10.3389/fimmu.2016.00607

43. Agaugué S, Marcenaro E, Ferranti B, Moretta L, Moretta A. Human natural killer cells exposed to IL-2, IL-12, IL-18, or IL-4 differently modulate priming of naive T cells by monocyte-derived dendritic cells. Blood. (2008) 112:177683. doi: 10.1182/blood-2008-02-135871

44. Apodaca MC, Wright AE, Riggins AM, Harris WP, Yeung RS, Yu L, et al. Characterization of a whole blood assay for quantifying myeloid-derived suppressor cells. J Immunother Cancer. (2019) 7:11. doi: 10.1186/s40425-019-0674-1

Conflict of Interest: The authors declare that the research was conducted in the absence of any commercial or financial relationships that could be construed as a potential conflict of interest.

Copyright (C) 2020 Market, Tennakoon, Ng, Scaffidi, de Souza, Kennedy and Auer. This is an open-access article distributed under the terms of the Creative Commons Attribution License (CC BY). The use, distribution or reproduction in other forums is permitted, provided the original author(s) and the copyright owner(s) are credited and that the original publication in this journal is cited, in accordance with accepted academic practice. No use, distribution or reproduction is permitted which does not comply with these terms. 